\title{
Investigating the use of concealable and disguised knives
}

The Police Journal: Theory, Practice and Principles

(C) The Author(s) 2017 Reprints and permission: sagepub.co.uk/journalsPermissions.nav DOI: $10.1177 / 0032258 \times 17694176$ journals.sagepub.com/home/pjx

\section{P F Mahoney}

ADMACC, Royal Centre for Defence Medicine, Medical Directorate, Joint Medical Command, ICT Centre, UK

\section{K Godhania}

Institute of Filipino Martial Arts, UK

\section{J Carr}

Impact and Armour Group, Centre for Defence Engineering, Cranfield University, Defence Academy of the United Kingdom, Shrivenham, UK

\begin{abstract}
Knife-carrying and knife crime is a significant issue in many countries. There are a number of knives available for purchase that are designed to be concealable, or that are disguised as everyday objects e.g. combs, pens and belts. In addition, an experienced knife-user will be able to conceal knives around their person. The aim of the work summarised in this paper was to study the concealment and deployment of a range of such weapons and to raise awareness of such threats to the blue-light community (police, ambulance, firefighters and other first responders); allow comment to be made on the effectiveness of various scenarios that a knife-carrier might use to carry and deploy a disguised or concealed knife; and measure the time to deployment of a disguised or concealed knife from different locations on an assailant's body so that suitable defensive responses can be designed and assessed. High-speed video was used to assist in studying attack sequences and allowed assessment of the speed of attack; this typically varied from 0.5 seconds to 2.3 seconds.
\end{abstract}

\section{Keywords}

Simulated attack, tissue simulant, blade, sharp-weapon, edged-weapon.

\section{Corresponding author:}

Dr Carr, Impact and Armour Group, Centre for Defence Engineering, Cranfield University, Defence Academy of the United Kingdom, Shrivenham SN6 8LA, UK.

Email: d.j.carr@cranfield.ac.uk 
Table I. Knife or sharp-weapon offences in the UK (20I5).

Type of offence

number of incidents

Assault with injury and assault with intent to cause serious harm

14,566

Robbery

10,432

Threats to kill

2,018

Attempted murder

354

Rape

334

Sexual assault

123

Homicide

181

\section{Introduction}

The blue-light community includes personnel within the police (law enforcement), healthcare and firefighting sectors, amongst others. These personnel are challenged by diverse threats during their employment. Violent threats include both blunt and penetrating trauma. Many personnel wear body armour to protect the critical organs of the torso, which are typically defined as the heart, lungs, liver, spleen and kidneys (Croft and Longhurst, 2007a, 2007b, 2007c; Lewis and Carr, 2016). Body armour design involves a compromise between protection and mobility and can leave significant areas of the body vulnerable to attack.

Knife-carrying and knife crime is considered a primary threat to the blue-light community. In many countries it is illegal to carry a knife. In the UK it is illegal to carry a knife that has a blade longer than $76.20 \mathrm{~mm}\left(3^{\prime \prime}\right)$. There are also a number of banned knife types and other sharp weapons, including disguised knives and concealable knives (HM Government, 2016). For the year ending December 2015 there were 28,008 offences in the UK involving a knife or sharp weapon; a $9 \%$ increase compared to the previous year (Office for National Statistics, 2016) (Table 1). Therefore, knife crime remains a very real threat to the modern blue-light community.

Whilst it is illegal in the UK to carry concealable or disguised knives, there are a number available for purchase that are designed to be concealable, or are disguised as everyday objects (e.g. combs, pens and belts). The study of concealed and disguised knives and their deployment has minimal coverage in the literature. A recent NHS England Safety alert (28 November 2016) raised the threat posed by hairbrush knives, illustrating that this topic needs to be more widely understood by health care providers.

Knife-fighting techniques are described in the military combat skills, martial arts and street survival literature, with additional published and online material emanating from the prison and gang-communities e.g. (Commander-in-Chief Staff Sections and Services, 1991; Elliott, 1917; Fairbairn, 1942; Grosz and Janich, 2006; Janich, 1993; Jenks and Brown, 1978; Kasper, 2009; MacYoung, 1990; Pentecost, 1988; Ryan, 1999). Military literature focuses on close combat scenarios such as hand-to-hand fighting and stealth trench raids (Commander-in-Chief Staff Sections and Services, 1991; Elliott, 1917; Engen, 2006; Fairbairn, 1942; Todd, 1938). Whilst the academic literature discusses the concealment of guns (Costanza and Kilburn, 2004; Costanza et al., 2013; 
Springwood, 2014), there are limited articles considering the concealment of knives e.g. (Engen, 2006; McCurry and Grossman, 2006; Todd, 1938).

Concealed knives maybe carried in a trouser belt or pocket, under a shirt, around the neck, hidden behind the wrist/lower arm/crossed arms or hands, in a boot or be disguised as everyday objects (Fairbairn, 1942; Janich, 1993; Jenks and Brown, 1978; Kasper, 2009; MacYoung, 1990; Ryan, 1999; Todd, 1938).

Several authors describe the importance of practising drawing a knife quickly and the stripping $^{1}$ of an upper body garment such as a T-shirt or shirt that might be over a concealed knife located in the waistband of a pair of trousers (Cassidy, 1975; Fairbairn, 1942; Kaspar, 2009; MacYoung, 1990; McCurry and Grossman, 2006). Knowledge of how such knives are concealed and subsequently deployed gives the prepared and trained individual an opportunity to avoid the attack or prepare a defence. Measuring the time taken for a knife to be deployed defines the time available for a defence to be prepared.

The aim of the work summarised in this paper was to study the concealment and deployment of a range of concealable and disguised knives and to:

1. raise awareness of such threats to the blue-light community (e.g. police, ambulance, fire-fighters and other first-responders);

2. allow comment to be made on the effectiveness of various scenarios that an individual might use to carry and deploy a disguised or concealed knife; and

3. measure the time to deployment of a disguised or concealed knife from different locations so that suitable defensive responses can be assessed.

\section{Method}

A hollow polymeric, headless, retail display male mannequin was purchased, cut in half along the mould line and used as a two-part mould to manufacture a simulated torso for the sharp-weapon assessment (Figure 1) (Cowper et al., 2016). The two halves of the polymeric mould were floated in a bath of cold water and filled with molten $\left(145^{\circ} \mathrm{C}\right)$ PermaGel $^{\mathrm{TM}}$. PermaGel ${ }^{\mathrm{TM}}$ has been previously used as a tissue simulant in sharpweapon, ballistic and blunt impact studies (Burrell et al., 2014; Cowper et al., 2016; Mabbott et al., 2013). After solidification (24 hours), the two halves of the torso were fitted together to form a three-dimensional PermaGel ${ }^{\mathrm{TM}}$ torso (Figure 1). The torso was mounted on a frame at a height equivalent to the 50th percentile height for the UK male population (1,760 mm) (Figure 1) (National Institute for Health and Care Excellence, 2016).

The knives used in this study were marketed as being concealable or disguised (Figure 2). Ethical approval for this study was granted by Cranfield University (approval number 1019_2016). Two expert sharp-weapons users participated in this study and provided signed consent to participate:

Krishna Godhania began his study of the martial arts 35 years ago, and has specialised in the Filipino martial arts (Kali-Eskrima-Arnis) for the past 28 years. He has studied these arts in the Philippines directly from indigenous Filipino Grandmasters, and also from Filipino Grandmasters based in the 


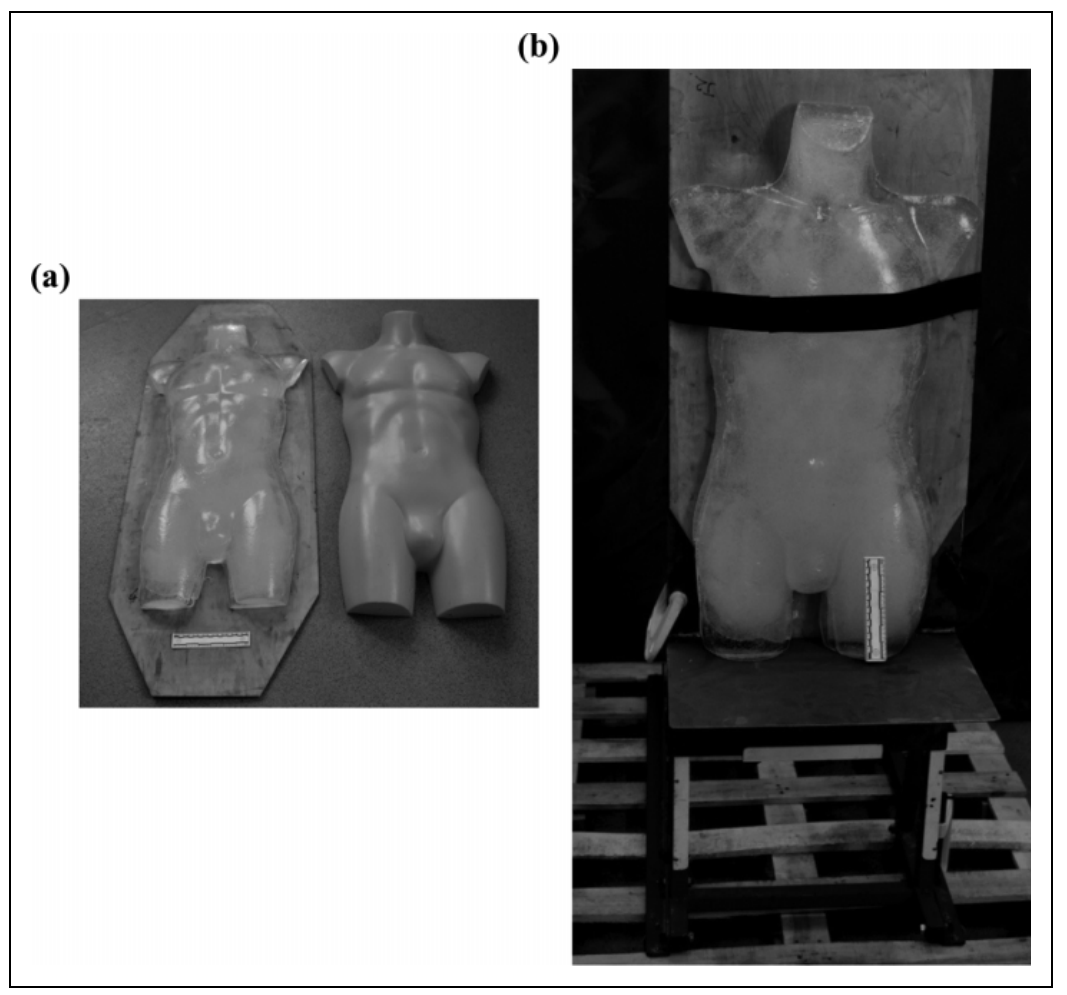

Figure I. Mould and PermaGel ${ }^{\mathrm{TM}}$ torso. (a) PermaGel ${ }^{\mathrm{TM}}$ torso (left) and retail mannequin (right). (b) Three-dimensional PermaGel ${ }^{\mathrm{TM}}$ torso mounted for testing.

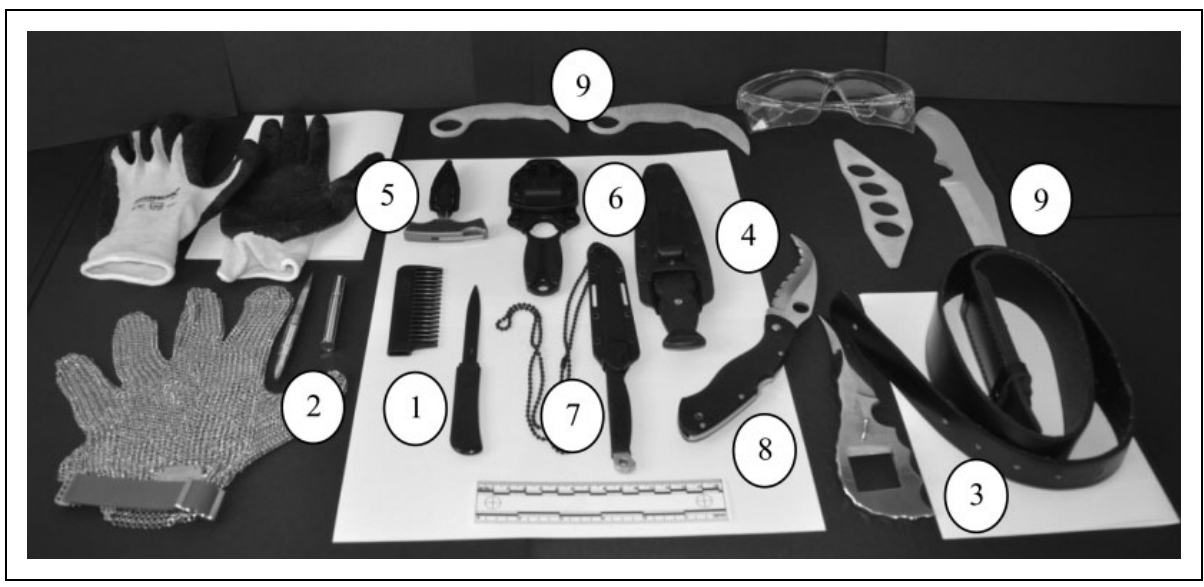

Figure 2. Knives and PPE used in the study (for an explanation of numbers, please see the Results section). 
USA. His book Filipino Eskrima is regarded as a standard reference on the subject. He is currently the only Full Instructor for the Sayoc Kali system in Europe and was consulted to demonstrate the speed and efficiency of blade accessing and deployment for this study. Sayoc Kali is a highly evolved Filipino system for understanding the use of edged weapons, and defensive solutions against them.

Peter Mahoney has over 40 years' experience of studying various martial arts, including weapon-based systems, and has over 30 years' clinical experience of both pre-hospital and in-hospital management of knife and ballistic injury.

Using each knife, an expert sharp-weapon user was asked to simulate an attack against the PermaGel ${ }^{\mathrm{TM}}$ torso. The expert was given no guidelines for the simulated attacks and was allowed to consider the most appropriate method to conceal and deploy the various weapons. Appropriate personal protective equipment (PPE) was worn by the expert users during testing (eye and hand/lower arm protection; Figure 2). A series of still photographs were taken using a Nikon D3200 DSLR camera fitted with an AF-S NIKKOR 18-55 mm lens for each attack demonstrating how the knife was concealed, drawn and used. A high-speed video (Phantom V12; resolution $640 \times 480$; 500 frames per second) was used to record each attack, allowing the expert's movement to be further analysed and to allow the length of each attack to be determined.

\section{Results}

The results are divided into (i) disguised knives and (ii) concealed knives. The method of concealment, draw and use are presented and described.

\section{Disguised knives}

The disguised knives considered in this study were a (i) comb, (ii) pen and (iii) belt (labelled 1 to 3 respectively in Figure 2). Figure 3 provides a series of photographs illustrating the concealment, draw and use of each of these knives.

The comb was placed in the inside pocket of a casual jacket and consisted of two parts, the blade being fixed in the handle of the comb. The comb was drawn from the pocket using the right hand and pulled through the hair with the left hand placed on top of the comb. As the comb reached the rear of the head the blade was pulled out from the remainder of the comb and the Perma-Gel ${ }^{\mathrm{TM}}$ torso was attacked. An alternative (and quicker) sequence involved removing the comb from the jacket pocket, immediately removing the blade and attacking the torso. The time taken for the two versions of comb attack from removal of the comb from the jacket pocket to impacting the torso was $1.1 \mathrm{~s}$ and $0.7 \mathrm{~s}$.

The pen was removed from the inside pocket of the jacket, the pen top removed and thrown at the Perma-Gel ${ }^{\mathrm{TM}}$ torso as a distraction tactic as the torso was attacked with the blade. The total time for the attack from removal of the pen top to the blade impacting the torso was $0.5 \mathrm{~s}$. 


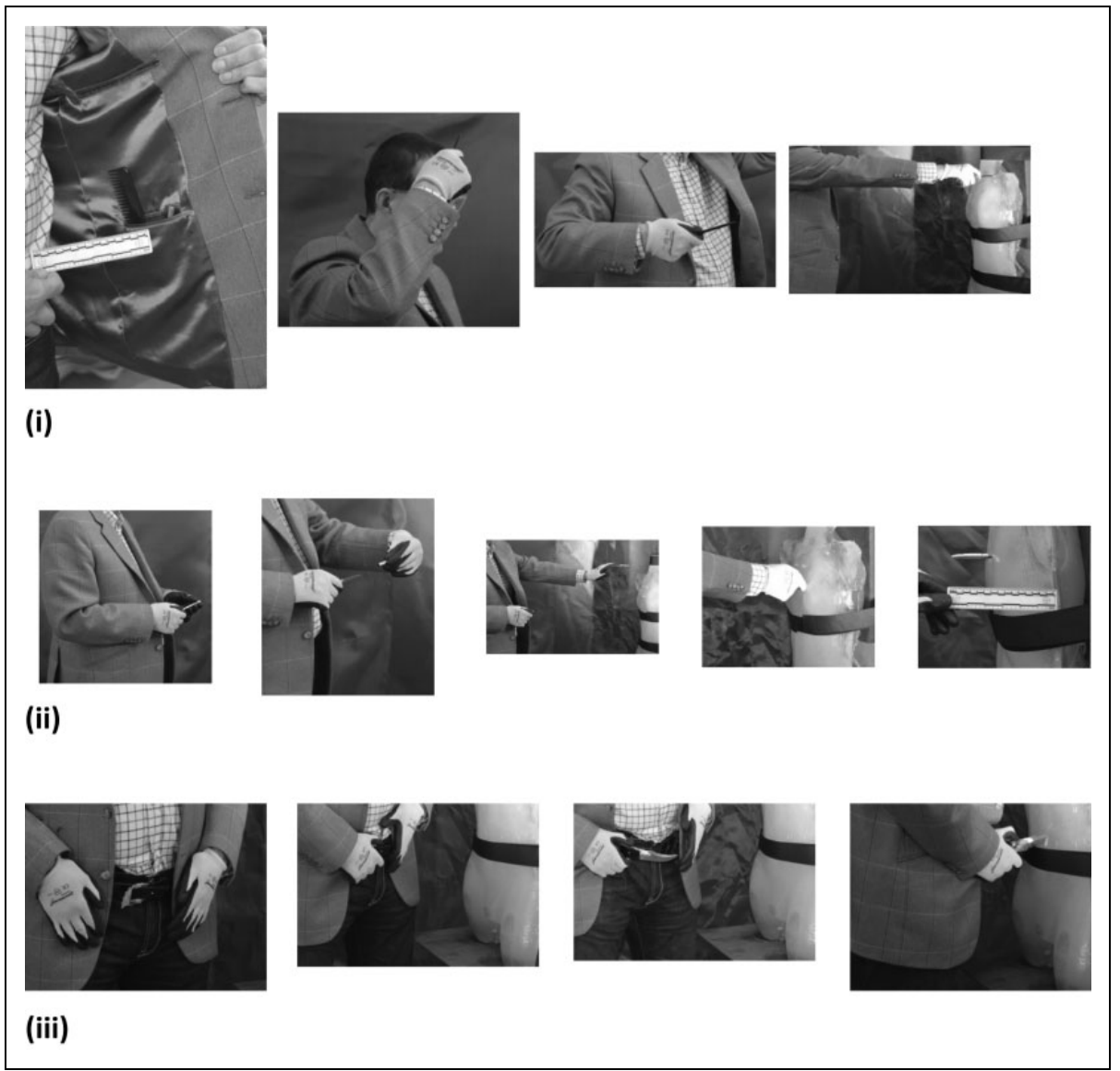

Figure 3. Concealment, draw and use of disguised knives: (i) comb, (ii) pen and (iii) belt.

The knife in the belt was located in the area of the buckle. Once released from the buckle, the knife was used to attack the Perma-Gel ${ }^{\mathrm{TM}}$ torso. However, because the blade remains attached to the belt, use of this weapon required the attacker to be located close to the victim. The total time for the attack was $1.7 \mathrm{~s}$.

\section{Concealed knives}

Concealed knives considered included those that were located in sheaths (clips) (i) on the waistband of a pair of trousers or on a belt, (ii) in a trouser pocket, (iii) in a boot or (iv) around the neck (labelled 4-7 respectively in Figure 2). Figure 4 provides a series of photographs illustrating the concealment, draw and use of each of these knives.

A knife concealed on a trouser waistband or a belt will usually be covered by a loose garment e.g. a T-shirt or shirt. The garment will need to be removed from the region of the knife so that the knife does not snag on it. In the current work, this was achieved by 

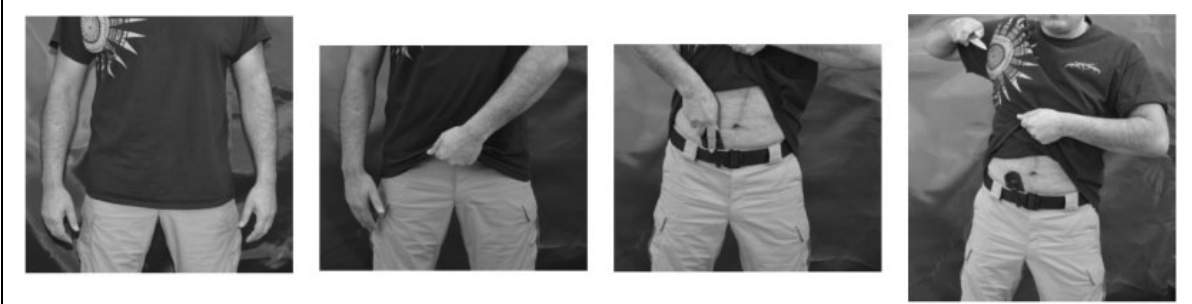

(i)
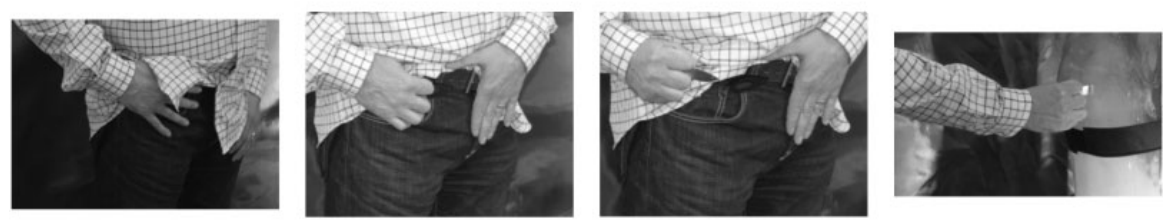

(ii)
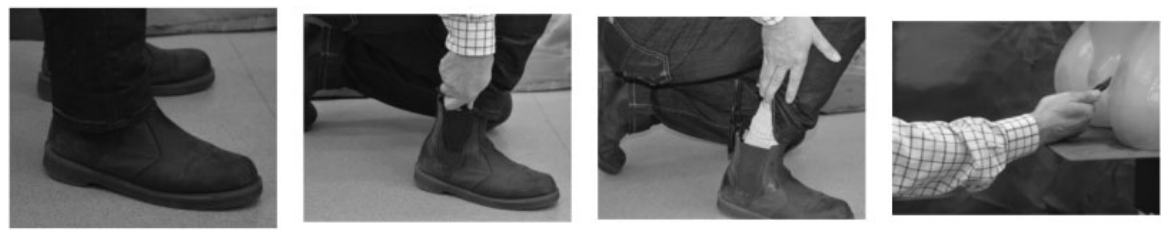

(iii)
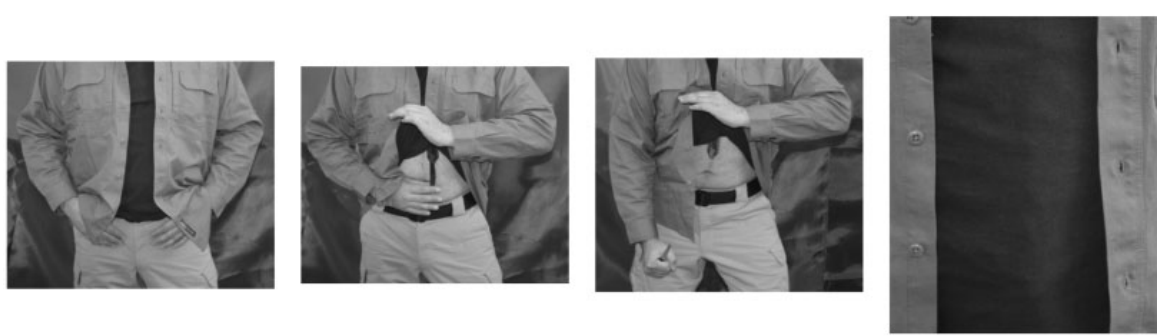

(iv)

Figure 4. Concealment, draw and use of knives: (i) trouser waistband, (ii) trouser pocket, (iii) boot and (iv) neck.

grabbing the bottom of the shirt or hooking the thumb of the non-knife hand under the bottom seam of the garment and pulling upwards. The attacker was then able to remove the knife from the sheath and perform the attack. The total time to attack using the knife in the waistband in Figure 4 was $1.4 \mathrm{~s}$. The expert noted that a quicker release might have been achieved if the fabric his trousers were made from had been stiffer e.g. denim. A 
slightly quicker attack was performed when the attacker initially stood with his thumbs hooked behind his trouser waistband, under his T-shirt.

Sheath-mounted knives concealed in trouser pockets are also usually covered with a loose upper garment such as a T-shirt or shirt. In Figure 4, a knife concealed in a trouser pocket was concealed using a shirt. The expert stood with his knife hand thumb hooked in the pocket, adding to the concealment but also resulting in a quicker draw compared to a hand held loosely by the side of the body, as the shirt was already slightly stripped from the knife. The non-knife hand was used to clear the shirt from the knife region before the attack occurred; a quicker attack could be achieved if the bottom button of the shirt was undone or if the garment worn had greater elasticity. The total attack lasted $1.8 \mathrm{~s}$. As the blade was short, the attacker stood relatively close to the Perma-Gel ${ }^{\mathrm{TM}}$ torso and noticeably twisted his non-knife hip towards the torso during the draw phase.

Boot knives are worn in sheaths located on the outside of the boot or at the rear. Either hand might be used to clear the knife before the attack is initiated. As the attacker had one knee on the ground, the body region impacted was below the waistline and typically the groin. The expert noted that ankle boots made from a stiff material (leather) and looser trousers would have increased the speed of the attack. The attack when a knife was drawn from the rear of the boot took $2.2 \mathrm{~s}$.

The knife worn on a neck sheath resulted in a visible deformation of the T-shirt worn on top of it. The expert disguised this (somewhat) by covering the T-shirt with a long sleeved shirt and stood with his thumbs hooked in his front trouser pockets, slightly hunching his back forward. The non-knife hand was used to clear the T-shirt from the knife, which was released from the sheath downwards. The resulting attack was low on the Perma-Gel ${ }^{\mathrm{TM}}$ torso, around the groin area. The attack took $1.5 \mathrm{~s}$.

Folding knives were also considered (number 8 in Figure 2). All of the above concealable knives have a metallic content; knives are also available that have no metallic content and thus are not easily detectable by various materials scanners. These include products similar to those labelled 9 in Figure 2. Figure 5 provides a series of photographs illustrating the concealment, draw and use of a folding knife and a nonmetallic content knife.

The folding knife was clipped in the right trouser pocket and the thumb of the right hand hooked in the pocket, adding to the concealment but also partially stripping the shirt from the knife. Hooking the thumb in the pocket partially removes the shirt and bunches it, meaning that it is easier to grab with the non-knife hand. The knife was then drawn, opened and deployed in one smooth movement. The attack sequence lasted $2.3 \mathrm{~s}$.

Several lower arm/wrist/hand concealment positions more commonly referred to as 'palming' are demonstrated in Figure 5 using one of the non-metallic knives. An attack sequence typically lasted $1.6 \mathrm{~s}$.

\section{Conclusions}

This research has demonstrated the concealment, draw and use of several knives specifically sold as concealable or designed to imitate everyday items. The use of such items allows a trained attacker to approach a target and engage them in $0.5-2 \mathrm{~s}$. This data provides a framework for the time required to mount a defence against such attacks. This 


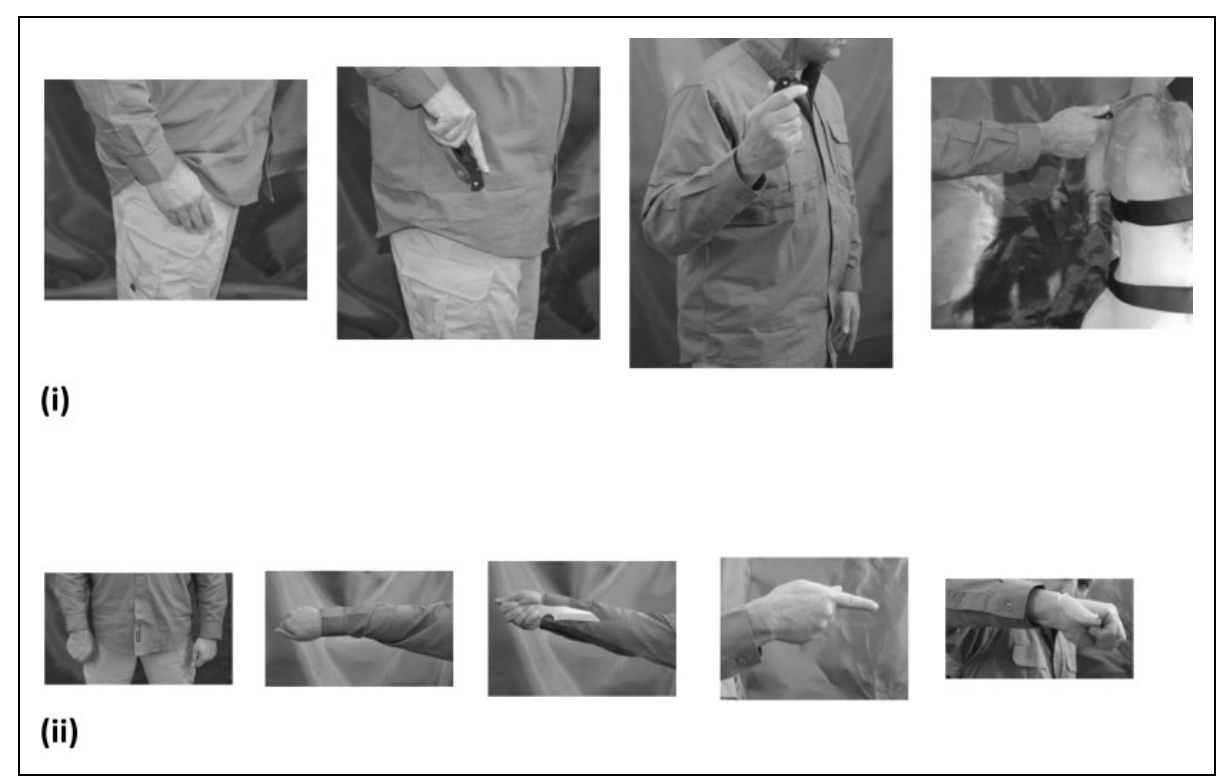

Figure 5. Use of a folding knife and a non-metallic content knife.

work has provided a series of images that personnel can use to assist them to assess possible threats from concealed/disguised knives. Specifically:

1. Beware if an upper garment is not tucked in, and the webbing of the hand between thumb and index finger is within the waistband of trousers/jeans/shorts. From this posture it is much quicker to clear the upper garment with the webbing of the hand compared with grabbing the upper garment and vertically pulling up. Loose clothing can disguise a weapon such as a neck knife. If the clothing is not loose, then an 'outline' of the sheath/blade is more likely to be visible. The development of ocular mapping skills to recognise such potential indicators is recommended.

2. If you cannot see the fingers of one hand but you can see the fingers of the other hand then this is an anomaly, and could indicate that a weapon is being palmed in the 'ice pick' grip. The deployment of a weapon from a palmed position will be quicker than a holstered position, and one should take that into consideration so as to maintain a reasonable reactionary gap distance.

\section{Acknowledgements}

The authors would like to thank police colleagues for access to weapons. Mr I Morton assisted with photography.

\section{Declaration of Conflicting Interests}

The authors declared no potential conflicts of interest with respect to the research, authorship, and/ or publication of this article. 


\section{Funding}

The authors received no financial support for the research, authorship, and/or publication of this article.

\section{Note}

1. That is, partially removing the garment from the body so that the knife can be drawn

\section{References}

Burrell G, Mabbott A, Carr DJ, Malbon C, O'Rourke S, Miller D and Teagle M (2014) Do underwire bras affect wounding potential during non-perforating ballistic impacts onto police body armour? In: Personal Armour Systems Symposium 2014 (PASS2014) (ed IPAC), Cambridge, UK, September 2014.

Cassidy WL (1975) The complete book of knife fighting Boulder, Colorado, USA: Paladein Press.

Commander-in-Chief Staff Sections and Services (1991) United States Army in the World War 1917-1919. Reports of the Commander-in-Chief, Staff Sections and Services. Volume 14, Washington D.C., USA: Center of Military History United States Army.

Costanza SE and Kilburn JC (2004) Circling the welcome wagons: area, income, race, and legal handgun concealment. Criminal Justice Review, 29, 289-303.

Costanza SE, Kilburn JC and Miles B (2013) The spatial dynamics of legal handgun concealment. Crime Mapping, 5, 39-62.

Cowper E, Mahoney PF, Godhania K, Carr DJ and Harrison K (2016) A pilot study examining garment severance damage caused by a trained sharp-weapon user. Textile Research Journal (accepted).

Croft J and Longhurst D (2007a) HOSDB Body Armour Standards for UK Police. Part 1: General Requirements Publication No. 39/07/A. Sandridge, St Albans: Home Office Scientific Development Branch.

Croft J and Longhurst D (2007b) HOSDB Body Armour Standards for UK Police. Part 2: Ballistic Resistance Publication No. 39/07/B. Sandridge, St Albans: Home Office Scientific Development Branch.

Croft J and Longhurst D (2007c) HOSDB Body Armour Standards for UK Police. Part 3: Knife and Spike Resistance. St Albans, United Kingdom: Home Office Scientific Development Branch.

Elliott FH (1917) Trench Fighting. Boston and New York, USA: Houghton Mifflin Company.

Engen R (2006) Steel against fire: the bayonet in the first world war. Journal of Military and Strategic Studies 8: 1-23.

Fairbairn WE (1942) All-in Fighting. Uckfield, East Sussex, UK: The Naval and Military Press Ltd.

Grosz C and Janich MD (2006) Contemporary knife targeting: modern science vs. W.E. Fairburn's timetable of death. Boulder, Colorado, USA: Paladin Press.

H.M. GOVERNMENT (2016) Buying and carrying knives [Online]. H.M. Government. Available: www.gov.uk/buying-carrying-knives (accessed 24 May 2016).

Janich MD (1993) Knife Fighting: A Practical Course. Boulder, CO: Paladin Press. 
Jenks HJ and Brown MH (1978) Prison's Bloody Iron: Deadly Knife Fighting Tactics Revealed. El Dorado, AR: Desert Publications.

Kasper B (2009) Sting of the scorpion. Boulder, Colorado, USA: Paladin Press.

Lewis EA and Carr DJ (2016) Personal armour. In Bhatnagar A (ed.) Lightweight Ballistic Composites: Military and Law-enforcement Applications. 2nd ed. Duxford: Woodhead.

Mabbott A, Carr D, Champion S, Malbon C and Tichler C (2013) Comparison of $10 \%$ gelatine, $20 \%$ gelatine and Perma-Gel ${ }^{\mathrm{TM}}$ for ballistic testing. Proceedings of the International Symposium on Ballistics, Freiburg, Germany, 22-26 April 2013, 648-654.

MacYoung MA (1990) Knives, Knife Fighting, and Related Hassles. Boulder, CO: Paladin Press. McCurry J and Grossman EL (2006) The top ten errors of martial artists defending against a blade. Journal of Asian Martial Arts 15: 36-53.

National Institute for Health and Care Excellence (2016) Weight, height and gender. Available at: www.evidence.nhs.uk/formulary/bnf/current/approximate-conversions-and-units/prescribingfor-children/weight-height-and-gender (accessed 10 December 2016).

Office for National Statistics (2016) Crime in England and Wales: Year Ending June 2016. London: UK Statistics Authority.

Pentecost D (1988). Put 'Em Down: Take 'Em Out. Boulder, CO: Paladin Press.

Ryan R (1999). Master of the blade: secrets of the Deadly Art of Knife Fighting. Boulder, CO: Paladin Press.

Springwood CF (2014). Gun concealment, display, and other magical habits of the body. Critique of Anthropology 34(4): 450-471.

Todd FP (1938). The knife and club in trench warfare, 1914-1918. The Journal of the American Military Foundation 2(3): 139-153. 